\title{
Essais
}

ESSAIS

Revue interdisciplinaire d'Humanités

Résister entre les lignes

\section{Resistencias de una variedad lingüística en peligro: estructura, usos y representaciones del criollo limonense (Costa Rica)}

Lucie Dudreuil

\section{(2) OpenEdition}

Journals

Edición electrónica

URL: http://journals.openedition.org/essais/4591

DOI: 10.4000/essais.4591

ISSN: 2276-0970

Editor

École doctorale Montaigne Humanités

Edición impresa

Fecha de publicación: 15 julio 2016

Paginación: 110-123

ISBN: 978-2-9544269-8-3

ISSN: $2417-4211$

Referencia electrónica

Lucie Dudreuil, « Resistencias de una variedad lingüística en peligro: estructura, usos y

representaciones del criollo limonense (Costa Rica) », Essais [En ligne], 9 | 2016, mis en ligne le 23 octobre 2020, consulté le 29 octobre 2020. URL : http://journals.openedition.org/essais/4591; DOI : https://doi.org/10.4000/essais.4591 


\title{
Resistencias de una variedad lingüística en peligro: estructura, usos y representaciones del criollo limonense (Costa Rica)
}

\author{
Lucie Dudreuil
}

¿Extinción o supervivencia? La cuestión de la evolución del inglés criollo limonense se plantea en estos términos según los lingüistas especialistas de la variedad, entre los que destaca la argentino estadounidense Anita Herzfeld ${ }^{1}$. El inglés criollo limonense es la variedad lingüística mixta que sobrevive en el Caribe costarricense y en algunas familias afrocostarricenses del Valle Central. En el año 2010, la UNESCO la declaró "lengua seriamente en peligro" en su Atlas Unesco de las lenguas del mundo en peligro ${ }^{2}$. Desde que llegara al Caribe costarricense a finales del siglo XIX tuvo que oponer resistencia, por su situación de diglosia, al uso e influencia de otros idiomas: la lengua oficial, es decir, el español y el inglés estándar, hablado por los capataces en las construcciones del ferrocarril y más tarde por los dueños de las plantaciones de la United Fruit Company. A lo largo de toda su historia, la resistencia lingüística en el Caribe costarricense se ha manifestado de manera proteiforme, en contextos sociohistóricos y políticos cambiantes y por tanto más o menos favorables. Pero no ha habido reivindicaciones lo suficientemente estructuradas y consensuadas como para influir en la adopción de un estatus legal y/o constitucional como ocurrió con el criollo de Bluefields en Nicaragua desde $1987^{3}$.

1 Anita Herzfeld, "Una evaluación de la vitalidad lingüística del inglés criollo de Limón: su vigencia o su desplazamiento", Revista de Filología y Lingüistica de la Universidad de Costa Rica, San José, Editorial UCR, julio-diciembre, 2011, p. 107-131.

2 Christopher Moseley, Atlas de las lenguas del mundo en peligro, $3^{\text {ra }}$ edición, París, Ediciones UNESCO, 2010. Disponible en : http://www.unesco.org/languages-atlas/index. php?hl=es\&page=atlasmap [Último acceso el 10/05/2015].

3 Ley $N^{\circ} 28$ de 1987 sobre el Estatuto de Autonomía de las Regiones de la Costa Atlántica de Nicaragua: Artículo 11: "El español es el idioma oficial del Estado. Las lenguas de las Comunidades de la Costa Atlántica de Nicaragua también tendrán uso oficial en los casos que establezca la ley", y también el Artículo 121, párrafo 5: "Los pueblos indígenas y las comunidades étnicas de la Costa Atlántica tienen derecho en su región a la educación intercultural en su lengua materna, de acuerdo con la ley". 
En el presente artículo recurriremos a la definición tradicional de resistencia lingüística basada en la oposición entre una lengua dominada y una lengua dominante, para cuestionar su validez a la luz de los trabajos de los filósofos franceses Gilles Deleuze y Félix Guattari ${ }^{4}$. Dichos trabajos, cuyo cometido era romper con el dualismo que caracteriza al estructuralismo5, versan sobre el concepto de rizoma aplicado al funcionamiento del pensamiento y a lo que más nos interesa: la lingüística. Este marco conceptual nos dará las herramientas para analizar la noción de resistencia lingüística no de manera dual, esto es, como una mera oposición entre dos códigos, sino como un entramado de usos y representaciones individuales y colectivas más complejo regido por cinco principios: el de "conexión", el de "heterogeneidad", el de "multiplicidad", el de "ruptura asignificante" y el de "cartografía". Relacionaremos este concepto de rizoma con el modo en que Édouard Glissant lo aplicara a la noción de identidad en los contextos criollos para poner de relieve el afán de homogeneización de las culturas dominantes que él denomina "atávicas". Según Édouard Glissant, las "culturas atávicas", basadas en la idea de que existen unas raíces únicas, aniquilan e intentan homogeneizar las diferencias culturales atribuyéndoles prejuicios negativos ${ }^{6}$. De manera general los criollos han recibido diversos glotónimos peyorativos y el criollo limonense no es una excepción. Así, destacan las denominaciones siguientes: bad english, broken english, flat english, patuá , etc. Ante estas representaciones peyorativas nos preguntaremos si las recientes propuestas literarias en criollo limonense pueden contrarrestar estos prejuicios y constituir un modo eficaz de resistir contra la homogeneización lingüística.

Primero, aplicaremos la noción de rizoma al criollo limonense para destacar la adaptabilidad constante inherente a su funcionamiento, lo que le otorga una capacidad de resistencia a pesar de no tener reconocimiento legal hasta la fecha de hoy. Esta asociación nos conducirá a identificar las fuerzas adversas contra las cuales tuvo y tiene que resistir y a ahondar en esas estrategias de resistencia. En particular, nos centraremos en los usos y representaciones del criollo limonense si es que existen de manera consciente para los hablantes. Por último, haremos hincapié en dos modalidades poéticas contemporáneas

4 Gilles Deleuze et Félix Guattari, Mille Plateaux, Paris, Éditions de Minuit, 1980, 645 p.

5 "La logique binaire et les relations biunivoques dominent encore la psychanalyse (l'arbre du délire dans l'interprétation freudienne de Schreber), la linguistique et le structuralisme, même l'informatique ». Gilles Deleuze et Félix Guattari, «Introduction : Rhizome », Mille Plateaux, 2007, p. 3. Disponible en : http://2007.updatepixels.net/2007/2007/hyper/rhizome.pdf [Último acceso el 10/05/2015].

6 Édouard Glissant, Introduction à une poétique du Divers, Paris, Gallimard, 1996, 144 p.

7 Este es un término que se usa tradicionalmente en el Caribe para referirse a las lenguas criollas. En particular, es muy usado en Jamaica y allí la grafía es "patwa". Cassidy, F.G. et R.B. LePage, Dictionary of Jamaican English, Kingston, University of West Indies Press, 2002, p. 494, [entrada de creole]. 
que usan esta variedad, para saber si más allá de ser un modo artístico original de resistir pueden contribuir de manera efectiva a la construcción y a la perennidad de esta variedad en peligro de extinción.

\section{El criollo limonense: un código rizomático, una resistencia "en potencia"}

Desde la antigüedad, las metáforas botánicas siempre han estado en el centro de toda actividad intelectual, ya sea artística o científica. ¿Acaso el arte no ha imitado y sigue siendo mimesis en cierta medida de la naturaleza? Se han utilizado para explicar nociones complejas y polisémicas tales como la identidad o el lenguaje. Las imágenes del árbol y de la raíz predominan en los estudios estructuralistas hasta mediados del siglo XX. A partir de los ochenta, los filósofos franceses Gilles Deleuze y Félix Guattari desarrollan una crítica al concepto de "árbol raíz". Según ellos se basa en una lógica binaria que imposibilita la aprehensión de la multiplicidad, característica fundamental del mundo y del ser humano ${ }^{8}$.

En cambio, la metáfora botánica del "rizoma” permite según ellos aprehender la noción de multiplicidad. En efecto, en botánica, el rizoma es un tallo subterráneo que crece horizontalmente. A diferencia de la raíz puede reunir dos o más elementos de naturaleza distinta. $\mathrm{O}$ sea representa perfectamente la idea de multiplicidad entendida como pluralidad contenida en una unidad. Por este motivo, las metáforas del rizoma y del manglar han tenido mucho éxito para dar cuenta de la complejidad de situaciones lingüísticas en áreas de plurilingüismo y de habla criolla. Richard Burton, especialista de la literatura martiniquesa, propone la del manglar. Define la situación lingüística de la isla del Caribe francés como "un manglar, o más bien un 'ecosistema' de manglares interconectados"”. Édouard Glissant, inspirado también por la aportación de Gilles Deleuze y Félix Guattari, tiende a cambiar la imagen de la raíz por la imagen del rizoma en su profusa reflexión sobre las identidades criollas. A su juicio, "La raíz única es la que mata cuanto existe a su alrededor, mientras que el rizoma es la raíz que se extiende para encontrarse con otras raíces ${ }^{10}$ ”. Cabe

8 "La logique binaire est la réalité spirituelle de l'arbre-racine. Même une discipline aussi "avancée" que la linguistique garde pour image de base cet arbre-racine qui la rattache à la réflexion classique (ainsi Chomsky et son arbre syntagmatique, commençant à un point $S$ pour procéder par dichotomie). Autant dire que cette pensée n’a jamais compris la multiplicité : il lui faut une forte unité principale supposée pour arriver à deux suivant une méthode spirituelle ». Gilles Deleuze y Félix Guattari, op. cit., 2007, p. 2.

9 "La situation linguistique est elle-même une mangrove, ou plutôt un "écosystème" de mangroves interconnectées ", Richard Burton, Le roman marron. Études sur la littérature martiniquaise contemporaine, Paris, L'Harmattan, 1997, p. 174.

10 "La racine unique est celle qui tue autour d'elle, alors que le rhizome est la racine qui s'étend à la rencontre d'autres racines ». Édouard Glissant, Introduction à une poétique du Divers, Paris, Gallimard, 1996, p. 7. 
recordar, como dijeron los filósofos franceses, que "el espíritu tiene retraso con respecto a la naturaleza" y el estudio del entorno natural puede proporcionarnos claves para entender nuestro funcionamiento interno y el de nuestras actividades sociales. El rizoma y los cinco elementos que lo caracterizan según los filósofos (la conexión, la heterogeneidad, la multiplicidad, el principio de ruptura asignificante y la cartografía) parecen particularmente ubérrimos a la hora de aprehender un contexto plurilingüístico en el que están en contacto lenguas estándares y criollos. La metáfora tiene un carácter hermenéutico que Paul Ricœur defiende en su famoso ensayo Metáfora viva ${ }^{11}$, pero no deja de ser un médium, una re-presentación de la realidad por analogía, un traslado, un desplazamiento. Como tal la metáfora del rizoma servirá de herramienta para interpretar y dar cuenta de manera visual del funcionamiento de una variedad eminentemente plural, que surgió y sigue evolucionando por el contacto de diferentes culturas, carácter que le ha permitido hasta ahora resistir a contextos particularmente adversos.

El criollo limonense funciona como una red de conexiones entre el acrolecto (variante del código más cercana a la norma estándar, en este caso el inglés estándar) y el basilecto (variante más criollizada y más alejada del inglés estándar). Es lo que los lingüistas especialistas de la criollística como Reinecke, Tokimasa et DeCamp ${ }^{12}$ llamaron "continuum lingüístico". Anita Herzfeld utilizó el concepto de continuum lingüístico para describir el funcionamiento del criollo limonense, insistiendo en que esos dos polos del continuum no pueden concebirse como dos entidades separadas, antes al contrario, pues entre los dos polos se establecen conexiones a todos los niveles (fonología, sintaxis y semántica).

El hablante hipotético "idealizado" de inglés estándar y el hablante de criollo no existen en Limón. Los hablantes usan formas de inglés estándar frecuentemente y formas criollas también, o al revés, pero ningún hablante usa exclusivamente formas de inglés estándar o formas criollas todo el tiempo. Esta variación en el uso está presente en la fonología, la sintaxis y la semántica ${ }^{13}$.

Se establecen también interferencias entre diversos códigos lingüísticos de ente diferente presentes en el Caribe costarricense, lo que le confiere a la variedad un carácter sumamente heterogéneo. Incorpora palabras de otros criollos ingleses, franceses y ahora sobre todo del español. La evolución de este código oral, que no tiene ni ortografía consensuada ni gramática normativa ${ }^{14}$,

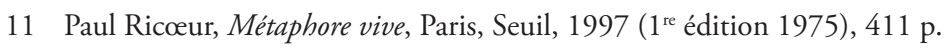

12 David DeCamp, "Toward a generative analysis of a post-creole continuum", Pidginization and creolization of languages, D. Hymes (ed.), Cambridge University Press, p. 349-370.

13 Anita Herzfeld, Mekaytelyuw: la lengua criolla, San José, Editorial de la Universidad de Costa Rica, 2002, p. 77.

14 El criollo limonense tiene reglas y existen gramáticas descriptivas del criollo limonense. Anita Herzfeld y Mario Portilla por ejemplo describieron usos y constantes gramaticales del 
es muy rápida. Entre 1870, momento en que la población afrocaribeña llega a Costa Rica para trabajar en la construcción del ferrocarril hacia el Atlántico y el año 2015, el código ha sufrido notables transformaciones. Al principio no incluía préstamos del español y ahora son cada vez más numerosos. Representan, según la estimación de Mario Portilla, el 19,6\% del léxico del código ${ }^{15}$. El español se inserta en la estructura misma del código. Conexión, heterogeneidad y multiplicidad, ya que el código no solo establece conexiones entre diferentes variantes, no solo es heterogéneo incluyendo varios códigos, sino que incluye el criterio de multiplicidad tal y como lo conciben Gilles Deleuze y Félix Guattari, es decir, como algo plural que "cambia necesariamente a medida que aumentan sus conexiones ${ }^{16 "}$. En efecto, el criollo que se habla en la Costa caribeña de Costa Rica ha ido cambiando notablemente a medida que han aumentado los contactos lingüísticos. El criollo jamaiquino que se hablaba a finales del siglo XIX se convierte en criollo limonense, variedad que a su vez integra más hispanismos y recientemente anglicismos de norma estadounidense, cuando el inglés lexificador del criollo era de norma británica, ya que Jamaica era una antigua colonia del imperio británico.

Queda por ver si los dos últimos principios, esto es, el de ruptura asignificante y el de cartografía son parte integrante del criollo limonense. Por el primer término los filósofos franceses entienden que la estructura del rizoma se organiza mediante líneas segmentarias que le permiten localizarse, y líneas de ruptura mediante las cuales puede des-localizarse. La ruptura es asignificante cuando esas líneas de fuga siguen formando parte del rizoma. La ruptura asignificante puede observarse en la integración reciente de anglicismos de norma estadounidense. La tendencia principal que consiste en incluir préstamos del español es, en cierta medida, una línea de fuga, pero es una tendencia constitutiva más del código y de su evolución que no se realiza de forma unidireccional. El último criterio Deleuze y Guattari lo contraponen al de calcomanía. El rizoma no calca la realidad, no la copia, sino que la cartografía, la construye. Es un sistema de representación que evoluciona y se actualiza sin cesar. La escritura libre que caracteriza este código oral puede considerarse también como un ejemplo de cartografía. Permite al código localizarse, fijarse pero nunca de manera definitiva ya que cada hablante puede escribirlo mediante una transcripción fonética que le es propia.

criollo limonense pero no existen gramáticas de tipo tradicional prescriptivas o normativas que etiquetan construcciones gramaticales como correctas o incorrectas.

15 Mario Portilla Chaves, "Intercambios léxicos entre el español y el inglés criollo de Limón”, Discurso de ingreso en la Academia Costarricense de la Lengua, leído el 16 de noviembre 2011 en la sede de la Academia Costarricense de la Lengua en San José, Costa Rica.

16 Gilles Deleuze y Félix Guattari, op. cit. , 2007, p. 4. 
El funcionamiento del criollo limonense reúne los cinco principios del rizoma, por eso hemos decidido considerarlo como un código rizomático. Su fuerte ductilidad le brinda potencialmente la capacidad de desarrollar estrategias eficaces de resistencia, pero se encuentra en una situación crítica. De ahí la necesidad de abordar la cuestión de la variación lingüística e identificar los diferentes factores de riesgo y las modalidades de resistencia.

\section{Resistencia lingüística "en acto"}

Una estructura rizomática propicia a las interferencias y al cambio lingüístico no presupone la vitalidad lingüística de un código, es decir, su transmisión intergeneracional. Es una condición y a la vez un signo de vitalidad lingüística en contextos sociopolíticos favorables pero en contextos adversos son estructuras particularmente vulnerables al fenómeno de "glotofagia" consustancial al conflicto lingüístico o a situaciones de diglosia que Louis-Jean Calvet define así:

La glotofagia es un proceso inherente a toda dominación colonial. Se puede observar a diferentes niveles: en discursos sobre las lenguas, en la organización de la comunicación social, el sistema de préstamos, la nominación del otro, la culpabilización lingüística, etc ${ }^{17}$.

Una lengua no es una estructura impermeable a los cambios históricos pero estos tampoco determinan totalmente la evolución de un código. Detrás del código están los locutores, quienes también tienen un margen de libertad en el uso de su lengua y aún más cuando se trata de criollos que carecen de gramáticas normativas. Para identificar las amenazas y analizar su impacto en la vitalidad lingüística del criollo limonense podemos recurrir al marco teórico propuesto por Chaudenson. Según el lingüista, la variación lingüística procede tanto de factores de tipo intralingüístico como de factores extralingüísticos o interlingüísticos y de sus interacciones. Los factores intralingüísticos serían aquellos que en el seno de sistema estructural propiciarían la sustitución de una forma por otra, mientras que los factores extralingüísticos serían la presión normativa, una situación de contacto, el estatus de un idioma... Los factores interlingüísticos serían las interferencias, como son por ejemplo los préstamos ${ }^{18}$.

En el caso del criollo limonense podemos destacar factores extralingüísticos, intralingüísticos e interlingüísticos que conjuntamente tuvieron un efecto particularmente negativo sobre la vitalidad de la variedad. El estado prohibió

17 « La glottophagie est un processus inhérent à toute domination coloniale. On peut la lire à différents niveaux : discours sur les langues, organisation de la communication sociale, système des emprunts, nomination de l'autre, culpabilisation linguistique, etc. ». Louis-Jean Calvet, "Glottophagie ", Sociolinguistique. Concepts de base, Liège, Mardaga, 1997, p. 155.

18 Robert Chaudenson, "Français avancé, "français zéro", créoles ", Actes du XVII Congrès de linguistique et philologie romanes, vol. 5 : Sociolinguistique des langues romanes, Aix-enProvence, Publications de l'Université de Provence, 1985, p. 165-180. 
el uso del criollo limonense en las escuelas públicas a mediados del siglo XX. Paradójicamente formaba parte del proceso de integración de la población afrocaribeña, que empieza claramente en 1948 en Costa Rica. Con la llegada de José Figueres al poder, el Estado otorga la nacionalidad costarricense a los afrocaribeños, que mayoritariamente llegaron para trabajar en la construcción del ferrocarril (San José-Puerto Limón) y en las plantaciones de la United Fruit Company. Como contrapartida se observa un fenómeno de aculturación forzada ${ }^{19}$. En aquella época la integración a nivel político se entiende más bien como homogeneización y adaptación de los usos y costumbres culturales de las minorías étnicas al sistema dominante. La prohibición del uso del criollo limonense en clase por los maestros y la supresión de las escuelas de inglés que estaban a cargo de las distintas iglesias protestantes fueron factores extralingüísticos tanto más perjudiciales cuanto que se acompañaron de una representación negativa del código, perceptible en los numerosos glotónimos peyorativos (bad english, broken english, flat english, patwa, etc.) usados tanto por la extracomunidad como por la intracomunidad aunque quizá con menor frecuencia muy recientemente. Tampoco goza de un reconocimiento constitucional ni legal, a diferencia de las lenguas indígenas que recientemente han adquirido el estatus de "lengua regional" por virtud del artículo 76 de la Constitución política de Costa Rica y de la ley n ${ }^{\circ} 7623$ del 29 de agosto de 1996 titulada Ley de Defensa del Idioma Español y Lenguas Aborígenes Costarricenses. Factores intralingüísticos e interlingüísticos se unen e interactúan con este contexto particularmente adverso y hasta prohibitivo a mediados del siglo XX. La extrema permeabilidad del criollo condujo al fenómeno que Anita Herzfeld denominó “injerencia del español”. Mediante esta expresión verbaliza el hecho de que el acrolecto del continuum lingüístico se está desplazando cada vez más hacia el español sustituyendo poco a poco el inglés jamaiquino estándar. Es un factor interlingüístico debido al contacto de lenguas pero es a la vez un factor intralingüístico porque se sistematizan los préstamos del español ${ }^{20}$ por comodidad. Es el caso de numerosas palabras en diversos campos semánticos tanto del entorno físico (fauna, flora,

19 El concepto "aculturación" aún es fuente de debate entre los sociólogos y etnólogos. Aquí empleamos la expresión "aculturación forzada" en el sentido que le da el sociólogo francés, Roger Bastide, cuando distingue diferentes tipos de aculturación. La "aculturación forzada" es la que se realiza cuando un grupo impone sus modelos culturales al otro. Así difiere de la "aculturación espontánea" o "planificada". Roger Bastide, anthropologie appliquée, Paris, Petite Bibliothèque Payot, 1971, $250 \mathrm{p}$.

20 Mario Portilla Chaves diferencia las interferencias léxicas debidas a fenómenos de alternancia de códigos de los préstamos que "pueden ser determinados con base en dos criterios: la frecuencia de uso del vocablo, que depende de su aceptabilidad por la comunidad de hablantes, y su adaptación a los patrones fonológicos de la lengua prestataria", "Intercambios léxicos entre el español y el inglés criollo de Limón”, Discurso de ingreso en la Academia Costarricense de la Lengua (leído el 16 de noviembre de 2011 en la Sede de la Academia, en San José de Costa Rica). 
fenómenos climatológicos etc.) como de la vida social (gastronomía, cultura, estado anímico, familia etc.) que se refieren a fenómenos característicos de la zona o de los costarriqueñismos como basiláar [vacilar (CR), divertirse(ES)] ${ }^{21}$. La conjunción de todos estos factores extra, intra e inter lingüísticos atenta contra la vitalidad lingüística del criollo limonense. Los abuelos y las personas de las viejas generaciones son aquellos que de manera casi exclusiva hablan la lengua. Los miembros de la generación adulta, si bien pueden comprenderla y a veces la hablan entre sí, no la transmiten de manera sistemática a los hijos. Los niños ya casi no la adquieren en sus familias como lengua materna, aprenden mayoritariamente el español, máxime cuando al menos uno de los dos padres tiene como lengua materna el español.

Frente a esta situación sociolingüística se han formado estrategias más o menos conscientes para resistir. Decimos más o menos conscientes porque ciertos locutores del criollo limonense dicen que hablan inglés o una variedad local del inglés por lo tanto no tienen la sensación de que la variedad criolla se encuentre en peligro. Entre los que sí tienen conciencia de hablar un criollo que se usa cada vez menos existen varias maneras de resistir. De manera colectiva se organizan talleres para nińos con cuentacuentos que trasmiten oralmente cuentos tradicionales como los de Anancy en criollo limonense ${ }^{22}$. Individualmente, ciertos padres decidieron hablar criollo limonense en casa y transmitirlo a sus hijos. Otros reivindican un estatus constitucional para el criollo limonense y, a falta de uno propio, el ya existente de las lenguas indígenas. La mayoría son sociolingüistas locutores nativos o no del criollo limonense. Dentro de este grupo de sociolingüistas intervencionistas encontramos entre otros a Esteban René Zúñiga Argüello y a Gloria Thompson que organizaron talleres para elaborar un alfabeto del criollo limonense en estrecha colaboración con la población. Está a punto de publicarse en la editorial costarricense EUNA. La ortografía siempre es un cuestionamiento delicado en el caso de las lenguas orales y requiere de una reflexión profunda que articule la naturaleza del código, su transcripción y el impacto sobre su evolución. Para otros lingüistas no intervencionistas como Mario Portilla un alfabeto puede ser interesante pero lo conciben más como una herramienta para investigadores, porque hasta el momento los locutores no formularon claramente la voluntad de tener uno. Mario Portilla fue el primero en crear una ortografía para el inglés criollo de Limón reservada a los investigadores y precisó su punto de vista:

21 Loc. cit.

22 Los cuentos de Anancy, la araña, son cuentos afrocaribeños de transmisión oral. Remontan al periodo de la esclavitud durante el cual se les enseñaba a los niños el cultivo de la astucia y llegaron a Costa Rica con la llegada de la población afrocaribeńa mayoritariamente jamaiquina. La tradición sigue viva hoy en día. El equipo audiovisual de la UNED y en particular Marvin Piedra grabó un documental sobre la transmisión de esos cuentos que se titula Anancy's Gift, UNED, San José, Costa Rica, DV Cam, 2010, 48 min. $50 \mathrm{sec}$. 
El propósito de este trabajo es, pues, proponer un alfabeto práctico para transcribir [...] los fonemas [...] de esta lengua. Esta ortografía fonemática está dirigida sobre todo a investigadores que necesiten realizar transcripciones fidedignas de la lengua, tales como lingüistas, etnólogos y antropólogos. Por otro lado, también está concebida para ser empleada por educadores [...]. Además este alfabeto práctico puede ser utilizado para facilitar la enseńanza de la ortografía inglesa estándar ${ }^{23}$.

La cuestión del posicionamiento del lingüista frente a su objeto de estudio divide a los lingüistas. Unos decidieron actuar sobre la lengua para proteger un código en peligro según la ONU. Otros piensan que no se puede intervenir sin el consenso de la población. En el caso del criollo limonense la solución a la disyuntiva de darle una ortografía o no parece tanto más difícil cuanto que no existe consenso entre la población local y si nos fijamos en las producciones literarias, el uso del código parece evolucionar en los dos sentidos: hacia la transcripción fonética escrita del criollo limonense y hacia una producción oral que se plantea transcribir el código mediante una publicación bilingüe en inglés estándar y en español.

La resistencia lingüística en acto no se reduce a una oposición binaria entre el criollo y la lengua oficial (el español) o entre locutores del criollo limonense contra los no-hablantes del criollo. Lo que sí parece verse a las claras es que hasta ahora no logró desmontar los prejuicios y la representación negativa del código. Para ser eficiente tiene que organizarse conjuntamente a todos los niveles intralingüísticos, extralingüísticos e interlingüísticos e implicar tanto a los locutores como a no locutores. Solo queda por ver, pues, el papel que desempeñan estas nuevas prácticas poéticas en la resistencia lingüística.

\section{Poesía en criollo limonense: nueva modalidad de resistencia lingüística}

A partir de los años 70, por primera vez, las editoriales nacionales publican obras de autores afrocostarricenses en editoriales nacionales. Es el inicio de las letras afrocostarricenses y, por ende, el de la difusión de nuevas voces que antes no se escuchaban. Se difunde una "visión intracéntrica" ${ }^{24}$ como la llama el intelectual Quince Duncan Moodie, primer escritor afrocostarricense en publicar una novela en español titulada Una canción en la Madrugada en el año 1970. A principios del siglo XX, los autores afrocostarricenses como Samuel Charles Nation, Can B. Soyes o J.B. Davidson publicaban ensayos

23 Mario Portilla Chaves, "Una ortografía para el criollo inglés de Costa Rica”, Revista de filología y lingüistica de la Universidad de Costa Rica, Vol.22, no.2, 1996.

24 Quince Duncan Moodie, "Corrientes literarias afrolimonenses", Puerto Limón: Formas y prácticas de auto/representación. Apuestas imaginarias y politicas, Perpignan, Presses Universitaires de Perpignan, 2012, p. 340. 
o poemas en la prensa local (The Atlantic Voice o The Searchlight) en inglés estándar. A mediados del siglo XX el uso del inglés estándar decayó notablemente, la lengua de publicación casi exclusiva era ya el español mientras que el criollo de Limón, por su parte, no aparece en producciones escritas. Se usa más bien para la transmisión de la literatura oral. Sin embargo, la poeta afrocostarricense Eulalia Bernard Little, primera mujer afrocostarricense en publicar un poemario Ritmohéroe en 1982, también es la primera en escribir un poema en inglés criollo de Limón mediante una transcripción fonética. Se trata de "What Fi Do?" recogido en el poemario My Black King publicado en 1991 y que reproducimos a continuación:

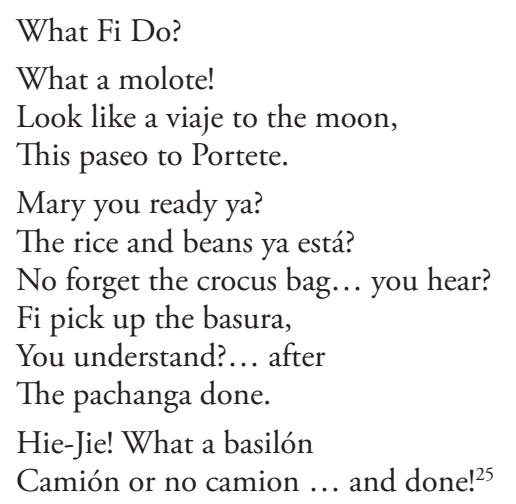

El uso del criollo limonense tiene implicaciones estéticas y éticas. Por una parte es la manera que ha encontrado Eulalia Bernard Little de desarrollar una poética sumamente rítmica y libre. El uso de un código heterogéneo le permite jugar con la entonación y las sonoridades pertenecientes a diferentes idiomas, rimando por ejemplo la palabra espańola basilón (del costarriqueñismo vacilar) con la palabra inglesa done. La ausencia de reglas normativas del criollo limonense le da también un margen de creación mayor como ella misma explica en una entrevista realizada por la profesora estadounidense Shirley Jackson:

Shirley Jackson: What are your thoughts on language?

Eulalia Bernard: We have not lost our intonation, which is very African. African Americans, for example, speak an African language with English sounds and structure. The Creole language, which is the oldest and newest thing we have, is rich, rhythmical, and fascinating. In Haiti, Limón and Jamaica, we speak with such freedom. Creole poems, which are not dry, are rooted in the way our people see the world. Whites, on the other hand, lost their Creole language, which became homogeneous without any distinguishing features ${ }^{26}$.

25 Eulalia Bernard Little, My Black King, Eugene, Oregon, World Peace University, 1991.

26 Miriam DeCosta-Willis, Daughters of the Diaspora, Afro-Hispanic Writers, Miami, Ian Randle Publishers, 2003, p. 125. 
Por otra parte, el uso del criollo limonense es un acto militante. Es parte de una lucha literaria y política que Eulalia Bernard emprendió como activista política contra las discriminaciones de las mujeres negras y en aras de la reivindicación de una identidad negra. Es una autora comprometida que introdujo en la Universidad de Costa Rica el primer curso sobre cultura negra en las Américas cuando era directora de los programas educativos televisivos en el Ministerio de Educación Pública. Su obra entera aspira a la deconstrucción de los estereotipos raciales y a la revisión de la historia costarricense insistiendo en los aportes de los indígenas y de los afrodescendientes.

Recientemente Marcia Reid Chambers ha desarrollado una producción poética oral en inglés criollo de Limón que va a ser transcrita por Mario Portilla en una publicación bilingüe en inglés estándar y en español. Marcia Reid Chambers es una poeta trovadoresca en el sentido de que su producción poética es esencialmente oral. Con esta práctica quiere transmitir el orgullo de su lengua materna y demostrar sus posibilidades creativas, sonoras y rítmicas. A continuación transcribimos un poema siguiendo la forma escogida por la autora, es decir, una transcripción bilingüe inglés estándar/español ${ }^{27}$ :

\begin{tabular}{|l|l|}
\hline \multicolumn{1}{|c|}{ Inglés estándar } & \multicolumn{1}{c|}{ Dialogue } \\
\multicolumn{1}{|c|}{ Long explanation } & \multicolumn{1}{c|}{ Espańol } \\
John died & \multicolumn{1}{c|}{ Diálogo } \\
Whose John? & Murió John explicación \\
Nora's boy & ¿Cuál John? \\
Which Nora? & El muchacho de Nora \\
Erick's Woman & ¿Cuál Nora? \\
Who is he? & La mujer de Erick \\
Ben's son & ¿Quién es ese? \\
Oh gosh & El hijo de Ben \\
Who is he? You don't hear? & iAy, Dios mío! \\
John the one who died & ¿Quién es ese?, ¿No me escuchas? \\
My sister's ex husband & John el que murió \\
Gosh, go away! & El ex marido de mi hermana \\
You talk and talk to tell me that & iAy! ¡Déjalo! \\
my sister's ex husband died & Toda esta conversación para decirme \\
& que el ex marido de mi hermana murió. \\
\hline
\end{tabular}

Destacan en la declamación del poema, la exploración de la oralidad por el uso del criollo limonense, la forma del diálogo y las numerosas aliteraciones, la tensión dramática alrededor de la identidad del difunto John hasta el desenlace final, el humor y la teatralidad con el lenguaje no verbal.

27 Para escuchar el poema "Dialogue/ Diálogo" de Marcia Reid Chambers se puede consultar el video realizado por la Universidad Estatal a Distancia.

Disponible en :

http://audiovisuales.uned.ac.cr/mediateca/videos/354/identidades.-ingl\%C3\%A9s-criollode-lim\%C3\%B3n, San José, UNED, 2010, $22 \mathrm{~min} .50 \mathrm{sec}$ - $23 \mathrm{~min}$. $32 \mathrm{sec}$. [Último acceso el 10/05/2015]. 
Usando el criollo de Limón como lenguaje poético ambas poetas resisten contra una serie de prejuicios negativos y dan esplendor a una variedad tradicionalmente excluida del círculo literario. Evidentemente no resulta suficiente para desmontarlos totalmente, para lograrlo sería necesaria una voluntad férrea de la población, combinada con una política lingüística institucionalizada no exenta de un enfoque educativo. Sin embargo Eulalia Bernard Little y Marcia Reid Chambers contribuyen cada una a su manera al cambio de representación connotativa del idioma. Si bien el uso poético no es una condición suficiente para rescatar el criollo limonense, ambas son propuestas artísticas que, además de darle vida a la variedad, pueden suscitar un interés nacional y/o internacional e impulsar una dinámica de protección institucionalizada.

\section{Reflexión final}

Desde que se publicaran los estudios estructuralistas, la resistencia lingüística se ha visto fundamentalmente como una oposición binaria entre lengua dominante y lengua dominada. Sin embargo esta manera de plantear la resistencia lingüística no tiene en cuenta el carácter heterogéneo de que puede estar constituida una variedad lingüística. El modelo del rizoma de Gilles Deleuze y Félix Guattari tiene el mérito de potenciar el estudio de la evolución de una variedad eminentemente heterogénea y sus interacciones con el ámbito interlingüístico y extralingüístico. Consideramos que puede ser una herramienta de análisis de los criollos en general, ya que éstos suelen estar compuestos de estructuras muy permeables al cambio lingüístico debido en parte a su uso menos normativo y al continuum lingüístico. No en vano, Gilles Deleuze y Félix Guattari concebían el rizoma como un modo de aprehender cualquier tipo de lengua ${ }^{28}$. La concepción tradicional de resistencia lingüística también ocultaba las posibles interferencias entre diferentes áreas. Recurrir de manera más sistemática al contexto sociohistórico, a los diferentes usos, a las actitudes individuales y colectivas de los locutores, a las representaciones de una lengua y ponerlos en relación con su estructura y su evolución permite entender de manera más completa una situación de resistencia lingüística. Darle un nuevo uso a una variedad lingüística, usarla como lenguaje

28 "Un rhizome ne cesserait de connecter des chaînons sémiotiques, des organisations de pouvoir, des occurrences renvoyant aux arts, aux sciences, aux luttes sociales. Un chaînon sémiotique est comme un tubercule agglomérant des actes très divers, linguistiques, mais aussi perceptifs, mimiques, gestuels, cogitatifs : il n'y a pas de langue en soi, ni d'universalité du langage, mais un concours de dialectes, de patois, d'argots, de langues spéciales. Il n'y a pas de locuteur-auditeur idéal, pas plus que de communauté linguistique homogène. La langue est, selon une formule de Weinreich, "une réalité essentiellement hétérogène". Il n'y a pas de langue-mère, mais prise de pouvoir par une langue dominante dans une multiplicité politique. La langue se stabilise autour d'une paroisse, d'un évêché, d'une capitale. Elle fait bulbe. Elle évolue par tiges et flux souterrains, le long des vallées fluviales, ou des lignes de chemins de fer, elle se déplace par taches d'huile». Gilles Deleuze y Félix Guattari, «Introduction : Rhizome », Mille Plateaux, 2007, p. 4. 
poético como hicieron Eulalia Bernard Little y Marcia Reid Chambers cuando no es habitual constituye un acto de rebeldía poética que participa de una resistencia lingüística que pretende perennizar la variedad e inmortalizarla sobre el papel o en la memoria colectiva.

La capacidad de resistencia de los criollos es inaudita por su estructura misma, y estas nuevas producciones poéticas son un buen ejemplo de resistencia "en acto". Aunque en la actualidad el contexto es más favorable al desarrollo de la variedad lingüística que a mediados del siglo XX, no existen marcos institucionales para la protección del criollo limonense. Su vitalidad futura dependerá en gran medida del apoyo institucional que reciba (un estatus legal y/o constitucional, la difusión de conocimientos acerca del código dirigida tanto a los afrocostarricenses como de forma más extendida a todos los costarricenses, su uso constitucional en las escuelas) para volver a incentivar la transmisión intergeneracional. La resistencia lingüística del criollo limonense tomará otras dimensiones el día en que aquélla trascienda los meros actos individuales o colectivos esporádicos, es decir, cuando se lleve a cabo una política lingüística acompañada de un programa educativo que tome en cuenta el carácter plurilingüístico de Costa Rica integrando no solo las lenguas indígenas sino también el criollo limonense.

Lucie Dudreuil

EA3656 Ameriber

Université Bordeaux Montaigne

ldudreuil0@gmail.com

\begin{abstract}
Resumen
Hoy en día el Atlas Unesco de las lenguas del mundo en peligro clasifica el inglés criollo limonense hablado en Costa Rica como "lengua seriamente en peligro". Una de las peculiaridades de este código es que su lengua lexificadora es el inglés en un país hispanohablante. A partir de finales del siglo XIX los hablantes de esta variedad lingüística mixta, calificada en este artículo de "rizomática", desarrollaron estrategias de resistencia conscientes o inconscientes en un contexto sociohistórico más o menos favorable. Este acercamiento teórico sacado del pensamiento de los filósofos franceses Gilles Deleuze et Félix Guattari permite ahondar el estudio de la resistencia lingüística saliendo de la oposición binaria entre lengua dominante y lengua dominada y preguntarse si las propuestas poéticas que surgen en inglés criollo limonense a partir de finales del siglo XX no serían nuevas manifestaciones de esta resistencia lingüística: una vía posible para perpetuar el uso de esta variedad en peligro de extinción.
\end{abstract}

\title{
Palabras claves
}

Sociolingüística, lenguas en contacto, inglés criollo, actitudes y representaciones lingüísticas.

\section{Résumé}

Actuellement plusieurs langues du Costa Rica sont recensées dans l'Atlas Unesco des langues en danger. Ce sont des langues indigènes pour la plupart mais un créole est également concerné. Il s'agit du créole de Limón (criollo limonense). L'une de ses particularités est que la langue 
lexificatrice de ce créole est l'anglais alors qu'il est parlé au sein de la Caraïbe hispanophone. À partir de la fin du XIX ${ }^{\mathrm{e}}$ siècle, les locuteurs de cette variété linguistique mixte que nous proposons de qualifier de "rhizomatique " ont développé des stratégies de résistance conscientes ou inconscientes dans un contexte socio-historique plus ou moins favorable. Cette approche empruntée aux philosophes français Gilles Deleuze et Félix Guattari permet d'envisager différemment la résistance linguistique traditionnellement conçue depuis le courant structuraliste comme une opposition entre langue dominante et langue dominée et de se demander si les propositions poétiques qui surgissent en anglais créole de Limón à partir de la fin du XXe siècle ne sont pas de nouvelles manifestations de cette résistance linguistique : une voie possible pour pérenniser cette variété en danger d'extinction.

\title{
Mots-clés
}

Sociolinguistique, langues en contact, créole, attitudes et représentations linguistiques, rhizome.

\begin{abstract}
Currently, several languages spoken in Costa Rica are said to be endangered by the UNESCO Atlas of World's Languages in danger. Most of them are indigenous languages, but one of those is Limonese Creole, a Creole spoken in a Spanish speaking country and whose lexifier is English. The speakers of this hybrid variety, we qualified as "rhizomatic", have developed, from the end of the XIX ${ }^{\text {th }}$ century, conscious or unconscious resistance strategies in an ever changing sociohistorical context. The term "rhizomatic" let us regard linguistic resistance no longer as an opposition between a dominant and a dominated language, as structural theory would. It also poses the question of whether or not the recent poetic manifestations in Limonese Creole can be considered as a new form of linguistic resistance: a possible way to ensure the survival of this endangered variety.
\end{abstract}

\section{Keywords}

Sociolinguistics, contact languages, creole, linguistic attitudes and representations. 